\title{
THE FUNDAMENTAL SPATIAL DATA IN THE PUBLIC ADMINISTRATION REGISTERS
}

\author{
V. Čada ${ }^{a}$, K. Janečka ${ }^{a}$ * \\ ${ }^{a}$ Department of Geomatics, Faculty of Applied Sciences, University of West Bohemia, Technická 8, Pilsen 30614, Czech Republic - \\ (cada, kjanecka)@kgm.zcu.cz
}

KEY WORDS: National Spatial Data Infrastructure, Fundamental Spatial Data, Basic Registers, Digital Economy

\begin{abstract}
:
The system of basic registers was launched in the Czech Republic in 2012. The system provides a unique solution to centralize and keep actual most common and widely used information as a part of the eGovernment. The basic registers are the central information source for information systems of public authorities. In October 2014, the Czech government approved the conception of The Strategy for the Development of the Infrastructure for Spatial Information in the Czech Republic to 2020 (GeoInfoStrategy) that serves as a basis for the NSDI. The paper describes the challenges in building the National Spatial Data Infrastructure (NSDI) in the Czech Republic with focus on the fundamental spatial data and related basic registers. The GeoInfoStrategy should also contribute to increasing of the competitiveness of the economy. Therefore the paper also reflects the Directive 2014/61/EU of the European Parliament and of the Council on measures to reduce the cost of deploying high-speed electronic communication networks. The Directive states that citizens as well as the private and public sectors must have the opportunity to be part of the digital economy. A high quality digital infrastructure underpins virtually all sectors of a modern and innovative economy. To ensure a development of such infrastructure in the Czech Republic, the Register of passive infrastructure providing information on the features of passive infrastructure has to be established.
\end{abstract}

\section{INTRODUCTION}

In October 2014, the Czech government approved the conception of The Strategy for the Development of the Infrastructure for Spatial Information in the Czech Republic to 2020 (GeoInfoStrategy) that serves as a basis for the NSDI. During the analytical stage of preparation of the GeoInfoStrategy the needs of all target groups were examined by a large survey. The main result from this survey was that the target groups (the public administration bodies, commercial sector and the public) working with spatial information require the availability and accessibility of fundamental spatial data at the highest level of detail (Ministry of the Interior of the Czech Republic, 2014). These fundamental data should cover the whole territory of the Czech Republic and be anchored in Czech Republic legislation. It is necessary to define the processes of their production, management, updating and provision. They will serve as a mandatory spatial data base not only for public administration but also for the needs of the whole society.

The strategic aim of the GeoInfoStrategy is to ensure the guaranteed services of public administration for the effective management and use of spatial information and wide use of these services by society. It is necessary to define the life situations when it is suitable and useful to use spatial information and services. This can't be reach without improving the quality and further development of the spatial data funds. It is necessary to define the spatial data sets that the public administration needs to cover all its activities. It is needed to define the content of the new National Set of Spatial Objects (NSSO) and prepare the legal, technical, institutional and economic conditions for its creation. NSSO is defined as the source of guaranteed and reference geographic data at the highest possible level of detail for selected objects of the real world covering the whole territory of the Czech Republic. NSSO will be widely used mainly in the decision making processes of public administration, by private sector and educational and research organizations. NSSO will be implemented as an information system at the governmental level with guaranteed standards of data quality, data flows and services.

The GeoInfoStrategy should contribute to increasing of the competitiveness of the economy. Therefore the paper also reflects the Directive 2014/61/EU of the European Parliament and of the Council on measures to reduce the cost of deploying high-speed electronic communication networks (European Parliament, 2014). The Directive states that citizens as well as the private and public sectors must have the opportunity to be part of the digital economy. A high quality digital infrastructure underpins virtually all sectors of a modern and innovative economy. To ensure a development of such infrastructure in the Czech Republic, the Register of passive infrastructure providing information on the features of passive infrastructure has to be established. The implementation of this Register is part of the strategy Digital Czech Republic 2.0 (Czech government, 2013).

\section{THE SYSTEM OF BASIC REGISTERS}

Before the GeoInfoStrategy, in 2012, the system of basic registers was launched (State Administration of Land Surveying, 2012) in the Czech Republic. The system provides a unique solution to centralize and keep actual most common and widely used information as a part of the eGovernment. The system consists of four main basic registers:

- Register of inhabitants,

- Register of persons (companies),

* Corresponding author 
- Register of territorial identification, addresses and real estates,

- Register of rights and responsibilities of public authorities.

The basic registers are the central information source for information systems of public authorities. The Register of territorial identification, addresses and real estates (RTIARE) can be then considered as a cornerstone of the Czech NSDI as mentioned in the GeoInfoStrategy.

Every RTIARE element consists of descriptive (a code and a name of the element) and positioning information. The positioning information includes a boundary and a definition point. RTIARE contains territorial elements (parts of the territory enclosed by boundaries), mainly:

- elements of the regional division (regions, municipalities, cadastre units etc.),

- parcels,

- building constructions with house numbers,

- addresses of building constructions.

Furthermore, RTIARE contains territorial units without boundaries, such as parts of municipalities, or streets (Čada and Janečka, 2016). It is absolutely necessary to ensure that RTIARE contains only valid data (Janečka and Hejdová, 2014), (Marvalová and Janečka, 2015).

\section{THE REGISTER OF PASSIVE INFRASTRUCTURE}

The GeoInfoStrategy contains several tens of measures. One of them is focused on a feasibility study of the Register of passive infrastructure. This register should provide detail information on the technical infrastructure to the public administration, commercial sector and the public.

It is obvious, that a proposal of this register stated in the GeoInfoStrategy was primarily focused on a spatial storage of the networks of technical infrastructure. These networks should be registered in the National Set of Spatial Objects and comply with the conditions of guaranteed data.

An example of the network of technical infrastructure is also the Next Generation Access (NGA) network for the high speed Internet. Next generation access networks mean wired access networks which consist wholly or in part of optical elements and which are capable of delivering broadband access services with enhanced characteristics (such as higher throughput) as compared to those provided over already existing copper networks. In most cases NGAs are the result of an upgrade of an already existing copper or co-axial access network. It means that in case of NGAs only wired access networks are allowed, no part of the network shall be wireless.

The vision of the strategy Digital Czech Republic (Czech government, 2011), that was approved by the Government of the Czech Republic in January 2011, is that in 2020 100\% of the citizens of the Czech Republic has an access to the Internet up to $30 \mathrm{Mbit} / \mathrm{s}$ and $50 \%$ of the citizens will be connected up to $100 \mathrm{Mbit} / \mathrm{s}$. The high speed Internet access project will be financially supported from the Operational Programme Enterprise and Innovations for Competitiveness ${ }^{1}$ - Priority axis 4: Development of high-speed internet access networks and information and communications technologies. To enable

\footnotetext{
${ }^{1}$ Ministry of Regional Development of the Czech Republic. European Structural and Investment Funds. Available online: http://www.strukturalni-fondy.cz/en/Fondy-EU/20142020/Operacni-programy/OP-Podnikani-a-inovace-prokonkurenceschopnost (accessed on 30 March 2016).
}

cofinancing from this operational programme a concept of the National strategy for NGAs development has to be drawn up first. The Ministry of Industry and Trade of the Czech Republic will submit this concept to the Government of the Czech government. The concept considers the NGAs as access networks which are capable of delivering broadband access services with enhanced characteristics as compared to those provided over already existing networks. The download should be at least $30 \mathrm{Mbit} / \mathrm{s}$.

The high speed Internet access project's aims are a modernisation and extension of the infrastructure of NGAs, especially a covering of so called white places. These are the places where is no access to the NGAs networks. This will require:

1. to modernise and extend the existing infrastructure for the high speed Internet access with using optical elements with aim to enable the download at least $30 \mathrm{Mbit} / \mathrm{s}$,

2. to create new networks partially or fully consisting of the fibre loops for the high speed Internet access enabling the download at least $30 \mathrm{Mbit} / \mathrm{s}$; in case of the newly built wired networks these networks have to enable the download at least $100 \mathrm{Mbit} / \mathrm{s}$,

3. to create a passive infrastructure to support the building of high speed Internet access, especially in locations of expected residential development.

The eligible cost in the Operational Programme Enterprise and Innovations for Competitiveness are, among others, the project documents cost, earth moving cost, documentation of actual construction cost, provided that they deal with white places. Their frequency will be evaluated from the survey on the infrastructure offering services of high speed Internet access. The survey was done in the form of a web questionnaire by the Czech Telecommunication Office in cooperation with the Ministry of Industry and Trade of the Czech Republic. For pointing to areas which are suitable for public intervention the colours (white, grey and black) are used depending on whether the private infrastructure already exists (Figure 1).

The public funding of deployment of broadband networks at the white places (almost rural areas), where no infrastructure exists, is generally considered unproblematic. At the black places (densely populated areas), where the competitive broadband infrastructure already exists, the public funding is forbidden, whereas the projects for grey places require more detailed analysis. The similar approach is also used in case of NGAs.

The draft law on measures to reduce cost of deploying highspeed electronic communication networks has been submitted. This law is a transposition of the European Directive 2014/61/EU on measures to reduce cost of deploying highspeed electronic communication networks (European Parliament, 2014) into the Czech national law. The transposition will also influence other laws ${ }^{23456}$.

The aim of these legislative adjustments is achieving of European Union objectives dealing with building of digital economy with sustainability economic and social benefits based on modern online services and fast Internet connectivity. The high-quality digital infrastructure is a basis for almost all parts

\footnotetext{
2 Act No. 127/2005 Coll., on electronic communications.

${ }^{3}$ Act No. 183/2006 Coll., on town and country planning and building code.

${ }^{4}$ Act No. 458/2000 Coll., on business conditions and public administration in the energy sectors and on amendment to other laws (the "Energy Act")

${ }^{5}$ Act No. 634/2004 Coll., on administrative fees.

${ }^{6}$ Act No. 416/2009 Coll., on acceleration of construction of a transport, water and energy infrastructure.
} 


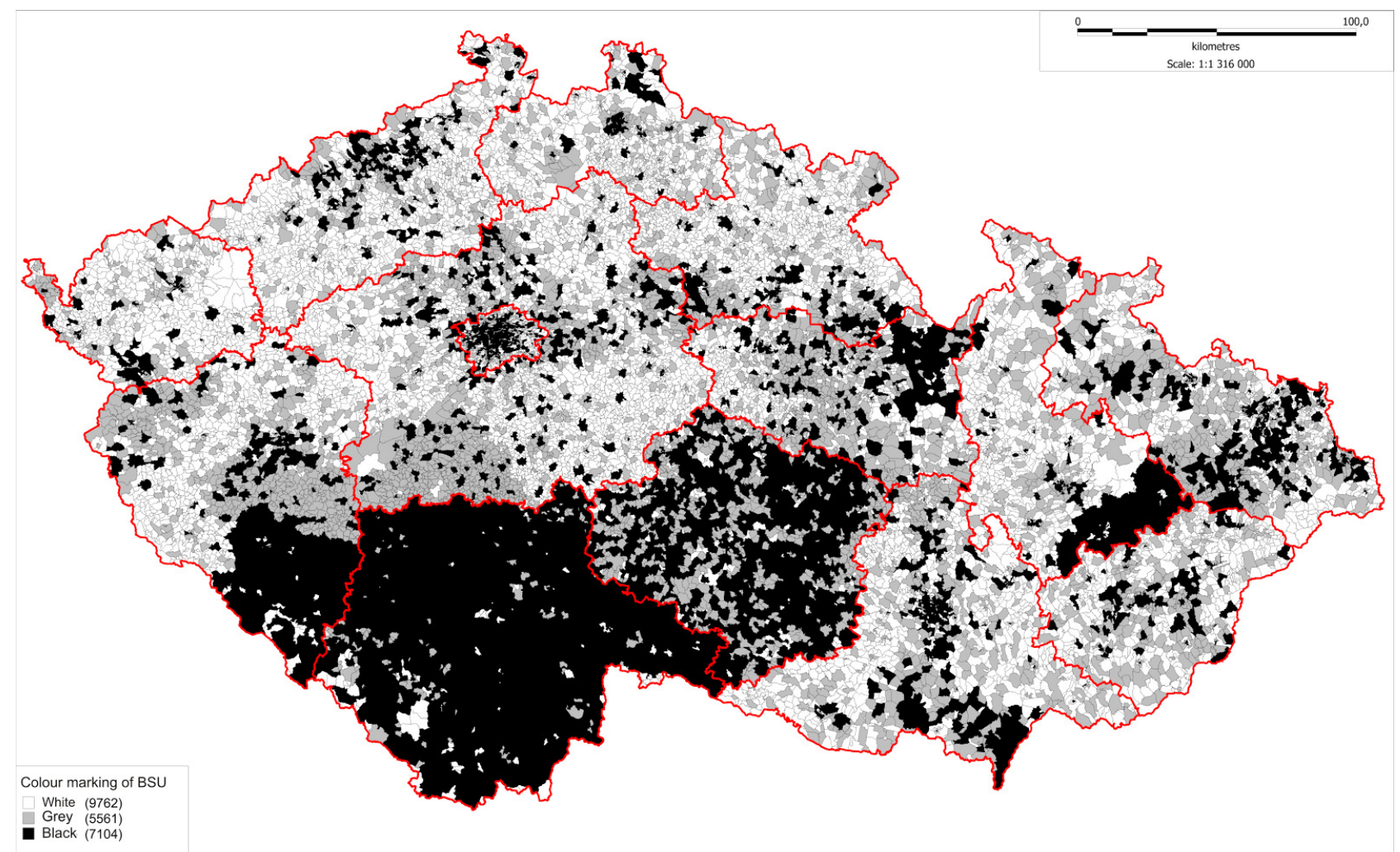

Figure 1. The indication map of white, grey and black places for basic settlement units (Czech Telecommunication Office, 2014).

of modern and innovative economic and has a strategic importance for social and territorial cohesion.

To ensure a development of NGAs the Register of passive infrastructure has to be established. The implementation of this Register is part of the strategies Digital Czech Republic (Czech government, 2011) and Digital Czech Republic 2.0 (Czech government, 2013). The Register of passive infrastructure will enable the efficient use of available information about the features of passive infrastructure gathered at one place. The information can be where necessary supplemented and shared by stakeholders. The realisation of the Register of passive infrastructure is a part of the implementation of the European Directive 2014/61/EU (European Parliament, 2014). This Directive obliges Member states to ensure an access to the information on the passive infrastructure through the single information point on 1 January 2017 at the latest.

The draft law on measures to reduce cost of deploying highspeed electronic communication networks establishes:

- creation of the single information point (further as SIP); the Ministry of the Interior of the Czech Republic should be this SIP,

- provision of information on physical infrastructure and electronic communications networks,

- the Register of physical infrastructure,

- provision of information on planning construction activities and on coordination of publicly funded construction activities,

- access to the physical infrastructure for the purpose of high-speed electronic communications networks building,

- competence of dispute settlement body (SIP).

The draft affects entrepreneurs providing or allowed to provide the physical infrastructure designated to provide services in the field of electronic communication, services of production, transmission or distribution of gas, power supply including public lighting, heating or water including waste water treatment, transport services including railways, roads, ports and airports. The draft will also affect competent administrative authorities (building authorities, relevant regulatory authorities) and to a lesser extent also entrepreneurs in the construction industry and owners of residential buildings.

The SIP's key role is to ensure full operational and functional integration of the Register of physical infrastructure. The implementation of the Register of physical infrastructure will enable the access of the authorised bodies to the information on physical infrastructure and will provide the data for production of digital technical maps, municipal plans or planning analytic materials.

The information on the physical infrastructure will be provided through the Information portal of SIP. It is necessary that managers of the physical infrastructure will provide highquality data into the Register of physical infrastructure. Furthermore, the Register has to be integrated with already existing information systems of public administration. Only in such case the Information portal of SIP can be effectively used. To ensure a long-term and conceptual development of the stateowned information and communication infrastructure a new state enterprise has been established - National Agency for Communication and Information Technologies (NACIT). The founder is the Ministry of the Interior of the Czech Republic.

\section{CONCLUSIONS}

The system of basic registers is built in the Czech Republic since 2009 as a comprehensive system containing the reference data for information systems of public administration and for all decision making process of public administration. Furthermore, the processes ensuring the sharing of data between basic registers themselves, between basic registers and public 
administration support information systems and between information systems themselves have to be defined and established.

The reference data in the basic registers are considered as valid, unless a doubt about the validity of reference data appears. In such case an editor of the register indicates this fact for particular data (record). From this moment the record has only an informative character and it lasts until the data are corrected. Effort to coordinate the activities of public administration bodies and commercial sector in the field of spatial information is reflected in the GeoInfoStrategy Action Plan (Ministry of the Interior of the Czech Republic, 2015). This Action Plan was approved in June 2015 by the Czech government and confirms a strong emphasis on the creation of the National Set of Spatial Objects (NSSO).

NSSO is defined as the source of guaranteed and reference geographic data at the highest possible level of detail for selected objects of the real world, covering the whole territory of the Czech Republic. NSSO will be widely used, mainly in the decision making processes of public administration, by private sector and educational and research organizations. NSSO will be implemented as an information system at the governmental level with guaranteed standards of data quality, data flows and services. NSSO will also enable a creation of the Register of passive infrastructure.

The administrator of NSSO will be responsible for building this information system and its maintenance. The important role of the NSSO administrator will be routine and continuous integration of the data contents. The concept of NSSO was firstly mentioned in (Čada, 2014).

The main advantage of having guaranteed and reference geographic data at the national level is that the data are collected once and used many times. The key benefit of reference data are lower cost for their updating and consistency between datasets and thematic data of users. The consistency of data should be ensured at a horizontal level and also at a vertical level between various levels of detail.

\section{ACKNOWLEDGEMENTS}

This publication was supported by the project LO1506 of the Czech Ministry of Education, Youth and Sports.

\section{REFERENCES}

Czech government, 2011. Digital Czech Republic Strategy. Available online: http://www.mpo.cz/dokument83642.html (accessed on 20 March 2016)

Czech government, 2013. Digital Czech Republic Strategy version 2 - A Way to the Digital Economy. Available online: https://ec.europa.eu/epale/en/node/6179 (accessed on 28 February 2016).

Czech Telecommunication Office, 2014. Available online: http://www.ctu.cz/cs/download/pruzkum_nga/mapy/ceska_repu blika_2014_bez-vymezeni_vysledna.png (accessed on 30 March 2016).

Čada V., 2014. The National Set of Spatial Objects and Its Properties. In: Proceedings of GIS Ostrava 2014 Geoinformatics in movement, publisher: VŠB - Technical University of Ostrava. ISSN 1213-239X. (In Czech0
Čada, V., Janečka, K., 2016. The Strategy for the Development of the Infrastructure for Spatial Information in the Czech Republic. ISPRS International Journal of Geo-Information, 5(3), 33; doi: 10.3390/ijgi5030033

European Parliament, 2014. Directive 2014/61/EU of the European Parliament and of the Council on measures to reduce cost of deploying high-speed electronic communications networks. Available online: http://eur-lex.europa.eu/legalcontent/EN/TXT/HTML/?uri=CELEX:32014L0061\&from=CS (accessed on 25 February 2016).

Janečka, K., Hejdová, J., 2014. Validation of Data of the Basic Register of Territory Identification, Addresses and Real Estates. In: Proceedings of the 5th International Conference on Cartography \& GIS, e-Proceedings, publisher: Bulgarian Cartographic Association, Riviera, Bulgaria, ISSN 1314-0604.

Marvalová, J., Janečka, K., 2015. Validation of Information and Relationships for Building Objects Registered in the Register of Territorial Identification, Addresses and Real Estates. Master's Thesis, University of West Bohemia, Faculty of Applied Science, Plzeň, Czech Republic. (In Czech)

Ministry of the Interior of the Czech Republic, 2015. Action Plan of the Strategy for the Development of the Infrastructure for Spatial Information in the Czech Republic to 2020. Prague, Czech Republic. (In Czech)

Ministry of the Interior of the Czech Republic, 2014. The Strategy for the Development of the Infrastructure for Spatial Information in the Czech Republic to 2020. Prague, Czech Republic. (In Czech)

State Administration of Land Surveying, 2012. Basic Registry Act, No 111/2009 Coll. Prague, Czech Republic. (In Czech) 